\title{
Planning and Conducting Magnetic Field Level Measurement from Overhead Transmission Line
}

\author{
H.M. Luqman, M.N.R. Baharom, H. Ahmad, Irshad Ullah \\ Faculty of Electrical and Electronic Engineering, Universiti Tun Hussein Onn Malaysia, Malaysia
}

\begin{tabular}{|c|c|}
\hline Article Info & ABSTRACT \\
\hline $\begin{array}{l}\text { Article history: } \\
\text { Received Aug 10, } 2017 \\
\text { Revised Nov 2, 2017 } \\
\text { Accepted Nov 16, } 2017 \\
\text { Keyword: } \\
132 \text { kV OTL } \\
\text { Construction site } \\
\text { LINDA wheel } \\
\text { Magnetic field level }\end{array}$ & $\begin{array}{l}\text { Human population and power consumption keeps on growing with each year. } \\
\text { In order to satisfy electricity demand, more electrical energy has to be } \\
\text { supplied, resulting in higher magnetic field level radiation. In rapid } \\
\text { urbanization country, lack of space will force civilization to be built near } \\
\text { overhead transmission line that sparks public concern on adverse health } \\
\text { effects due to the magnetic field radiation. A new UTHM hostel residential } \\
\text { area was built near OTLs that shared the same concern. Thus a proper } \\
\text { planning to conduct magnetic field level measurement was done to examine } \\
\text { the maximum magnetic field level radiated that covered the hostel residential } \\
\text { area. The results were far from reaching the maximum permissible magnetic } \\
\text { field level proposed by ICNIRP. Though, the steps taken and the methods } \\
\text { used might be suitable guidelines for others that encounter similar situations. } \\
\text { Copyright } \odot 2017 \text { Institute of Advanced Engineering and Science. } \\
\text { All rights reserved. }\end{array}$ \\
\hline $\begin{array}{l}\text { Corresponding Author: } \\
\text { H.M. Luqman, } \\
\text { Faculty of Electrical and Electronic Eng } \\
\text { Universiti Tun Hussein Onn Malaysia, } \\
\text { 86400 Batu Pahat, Johor, Malaysia. } \\
\text { Email: luqman_h317@yahoo.com }\end{array}$ & leering, \\
\hline
\end{tabular}

\section{INTRODUCTION}

OTL is a medium used solely to provide electricity from one place to another. The rate of electricity consumption in Malaysia increased with time due to high industrial productivity and rapid urbanization. In order to satisfy the high demands of electricity, new OTLs were constructed as well as upgrading the existing ones. The electrical energy transmitted through OTL produced high strength of magnetic field and electric field to the surroundings that have been the concern of previous researchers regarding the effect it may give to human health [1-3]. Prolonged exposure to electric fields show no significant results in adverse health effects, but the same results have been an open question when exposed to weak magnetic fields [4]. Among the health effects that are heavily being discussed in relation to magnetic field exposure are the increase of brain cancer and leukemia.

The population growth rate in Malaysia from 2010 until 2016 has increased roughly 3.4 million people $(12.11 \%)$ and the numbers keep on increasing every year. In parallel with the population growth, civilization will be forced to be built near OTL and people will be concerned with the EMF radiated [5]. Thus the International Commission on Non-Ionizing Radiation Protection (ICNIRP) and other incredible organizations took the effort to establish guidelines for the protection of humans exposed to electromagnetic fields (EMF) in the low-frequency range of the electromagnetic spectrum against all established adverse health effects. ICNIRP provide separate guidance of exposure for occupational and general public categories. The former refers to adults exposed to time-varying electric and magnetic fields from $1 \mathrm{~Hz}$ to $10 \mathrm{MHz}$ at their workplaces, generally under known conditions, and as a result of performing their regular or assigned job activities. The latter covers individuals of all ages and of varying of the individual health status which might increase the variability of the individual susceptibilities in which many are unaware of their exposure to 
EMF. The magnetic field flux density reference levels for both categories are $1000 \mu$ Tesla and $200 \mu$ Tesla respectively [6].

In the year of 2015, a new hostel residential area for UTHM students was constructed within the area of Taman Bintang, Parit Raja. A number of nine five-storeyed building blocks were built within the vicinity of $132 \mathrm{kV}$ and $275 \mathrm{kV}$ OTLs as shown in Figure 1. Block 9 is located the nearest to the $275 \mathrm{kV}$ pylon tower at about 22.5 meter distance. Parking lots were located directly underneath the span length of the $132 \mathrm{kV}$ OTL cables. Students will spend most of their time living, eating, sleeping and studying for about one to two years knowing or unknowingly that they are exposed to magnetic field radiated from the OTLs. It was when the construction had taken place that the concern for magnetic field radiation had been raised. Thus a team of six members were organized to conduct magnetic field measurement in order to determine whether or not the magnetic field radiation emitted from the OTL is permissible as according to the standards proposed by ICNIRP.

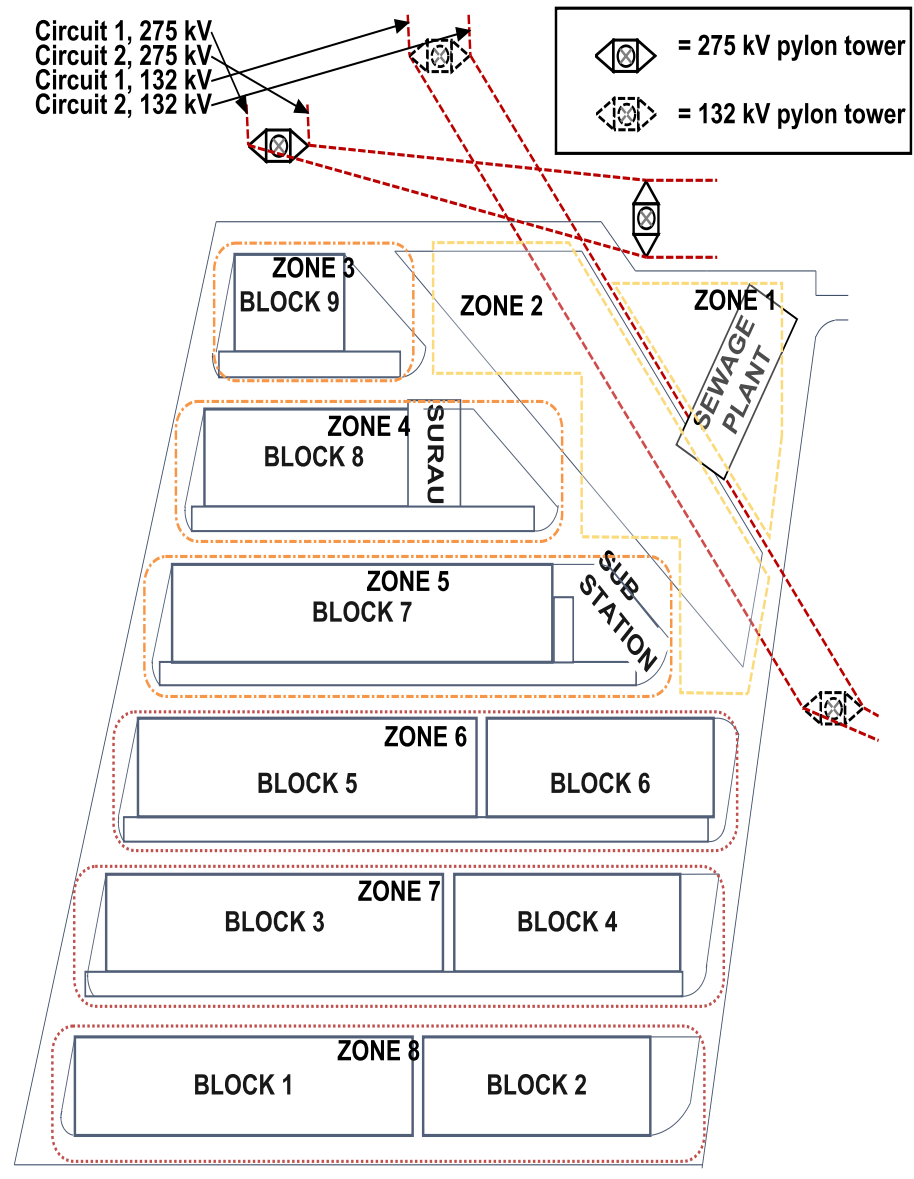

Figure 1. UTHM Taman Bintang new student hostel residential area plan layout

The objective of the magnetic field measurement was to record and provide magnetic field level radiated from $132 \mathrm{kV}$ and $275 \mathrm{kV}$ OTLs to the vicinity covered by the UTHM residential area within a week from 8 a.m. until 4 p.m. Provided in this paper are the planning on magnetic field level measurement procedures throughout the process. Measurements took place while the construction was still in progress.

\section{RESEARCH METHOD}

Before conducting magnetic field level measurement outdoors, especially a large scale measurement, it is best to prepare a proper plan to avoid huge consumption of time, energy and costs. In this section, the planning used for magnetic field level measurement done by the authors is described in detail.

Figure 2 shows the flowchart of the magnetic field level measurement planning process. 


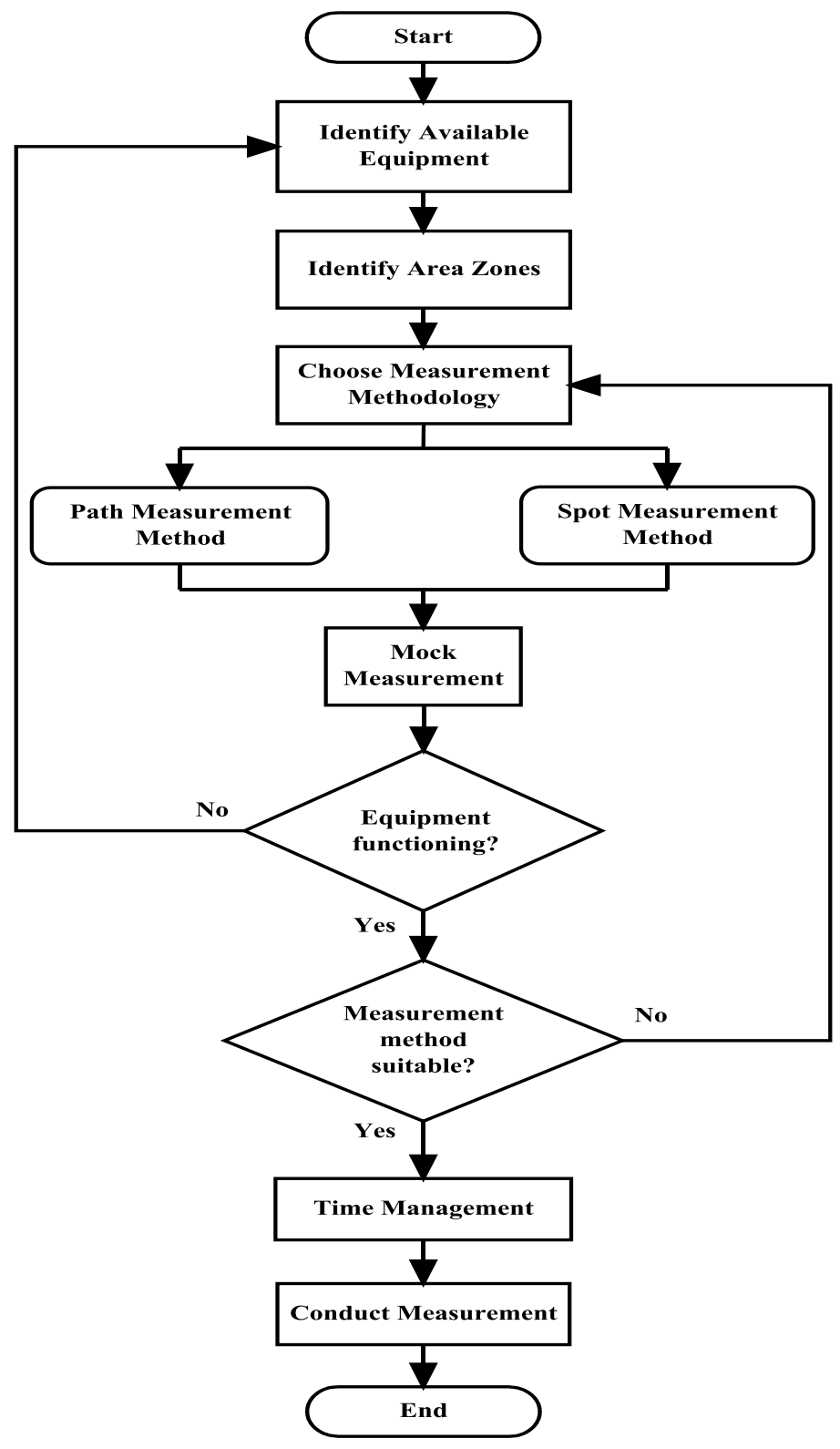

Figure 2. Flowchart of magnetic field level measurement planning process

\subsection{Equipment}

The first step taken was to identify the availability of magnetic field level measurement equipment. Two types of equipment were used, which were Gauss Meter and EMDEX II Meter, both with detection limit of $0.01 \mu$ Tesla. Gauss Meter can only be used to read magnetic field level that had to be recorded manually while EMDEX II Meter was operated with LINDA Wheel to read and record magnetic field through a path automatically and transferred to a laptop. Both of the equipment were tested inside a laboratory with the high amps wireless transfer using loop antenna method as recommended by IEEE Standard [7]. The equipment sensors were placed pointing into three different directions; direction 1 (as shown in Figure 3), direction 2 (sensor pointing towards the sky) and direction 3 (sensor pointing towards the magnetic field generator). Table 1 shows the accuracy the equipment tested that was less than 10\% error and acceptable according to IEEE Standards [7].

The initial plan was to use both magnetic field meters in every magnetic field level measurement that would serves as backup in case one of the equipment encountered any sort of problem. Though, during the measurement, there were areas that only used one magnetic field meter due to time constraint and geographical topology limitations. 


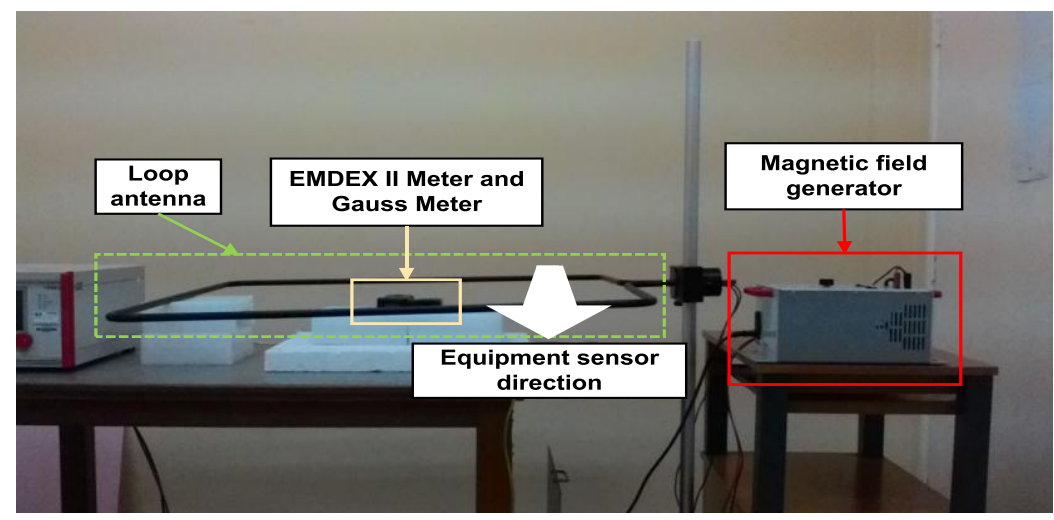

Figure 3. High amps wireless transfer using loop antenna testing (equipment sensor in Direction 1)

Other notable equipment used during the measurement was safety equipment (boots, helmets, vests, and etc.), measuring tape, spray paints and nails for ground-marking purposes.

Table 1. High amps wireless transfer using loop antenna test results for different directions

\begin{tabular}{|c|c|c|c|c|c|c|c|}
\hline \multirow[b]{2}{*}{ Equipment } & \multirow{2}{*}{$\begin{array}{c}\text { Expected } \\
\text { Result } \\
(\mu \text { Tesla })\end{array}$} & \multicolumn{2}{|c|}{ Direction 1} & \multicolumn{2}{|c|}{ Direction 2} & \multicolumn{2}{|c|}{ Direction 3} \\
\hline & & $\begin{array}{c}\text { Result } \\
(\mu \text { Tesla) }\end{array}$ & $\begin{array}{c}\text { Error } \\
(\%)\end{array}$ & $\begin{array}{c}\text { Result } \\
(\mu \text { Tesla })\end{array}$ & $\begin{array}{c}\text { Error } \\
(\%)\end{array}$ & $\begin{array}{c}\text { Result } \\
(\mu \text { Tesla) }\end{array}$ & $\begin{array}{c}\text { Error } \\
(\%)\end{array}$ \\
\hline EMDEX II & 1.26 & 1.30 & 3.17 & 1.20 & 4.76 & 1.30 & 3.17 \\
\hline Meter & 3.77 & 3.90 & 3.45 & 3.66 & 2.92 & 3.86 & 2.39 \\
\hline Gauss Meter & $\begin{array}{l}1.26 \\
3.77\end{array}$ & $\begin{array}{l}1.16 \\
3.54\end{array}$ & $\begin{array}{l}7.94 \\
6.10\end{array}$ & $\begin{array}{l}1.17 \\
3.57\end{array}$ & $\begin{array}{l}7.14 \\
5.30\end{array}$ & $\begin{array}{l}1.23 \\
3.69\end{array}$ & $\begin{array}{l}2.38 \\
2.12\end{array}$ \\
\hline
\end{tabular}

\subsection{Area Zoning}

The area of interests to measure the magnetic field level was the area directly underneath the $132 \mathrm{kV}$ OTL cables because this would be the area with the highest reading of magnetic field level. Other interest was the magnetic field level measurement along the perimeter of each building block as students will spend most of their time inside these buildings.

In order to provide a more systematic measurement procedure, the huge area was divided into eight zones that were grouped according to priority. Priorities were given in order to ensure the continuity of magnetic field level measurement in important areas. Every magnetic field level measurement procedures done were started at zones with the highest priority. Priority 1 consists of Zone 1 and Zone 2 that covered the areas directly underneath the $132 \mathrm{kV}$ OTL and towards the main entrance of the hostel residential area. Priority 2 consists of Zone 3, Zone 4 and Zone 5 where the building blocks were located near to the $132 \mathrm{kV}$ OTL. Priority 3 consists of Zone 6, Zone 7 and Zone 8 where the building blocks were located far from the $132 \mathrm{kV}$ OTL.

\section{MEASUREMENT METHOD}

The BSI Standards were used as guidelines in order to measure and record the magnetic field radiated from OTL that provides the characteristics and requirements for magnetic field meters, measurement procedures and on how to report field measurements in general. In this measurement both Gauss Meter and EMDEX II Meter were attached to LINDA Wheel to maintain the height of 1 meter above ground as required by the single-point measurement in accordance to BSI Standards [8].

Two types of magnetic field level measurement method were used throughout the measurement in accordance to the availability of magnetic field meters, namely spot measurement method and path measurement method. Path measurement method was not used in Zone 1 and Zone 2 due to the geographical area in these two zones which were muddy and unlevelled making the LINDA Wheel to be inoperable in such circumstances. The measurements conducted along the building blocks perimeter were done at a distance of 3 meters from the walls after taking into consideration for the safety of team members. Only path measurement method was used in Zone 6, Zone 7 and Zone 8 due to time constraints. 


\subsection{Path Measurement Method}

Path measurement method was used in this measurement by using EMDEX II Meter that was operated together with LINDA Wheel. The combination of these two equipment made it possible to read and record magnetic field level measurement along a distance traveled. This method was used mainly for the magnetic field level reading around of building blocks perimeter as shown in Figure 4. The path traveled using this method will start and end on Point A in clockwise direction for all of the zones.

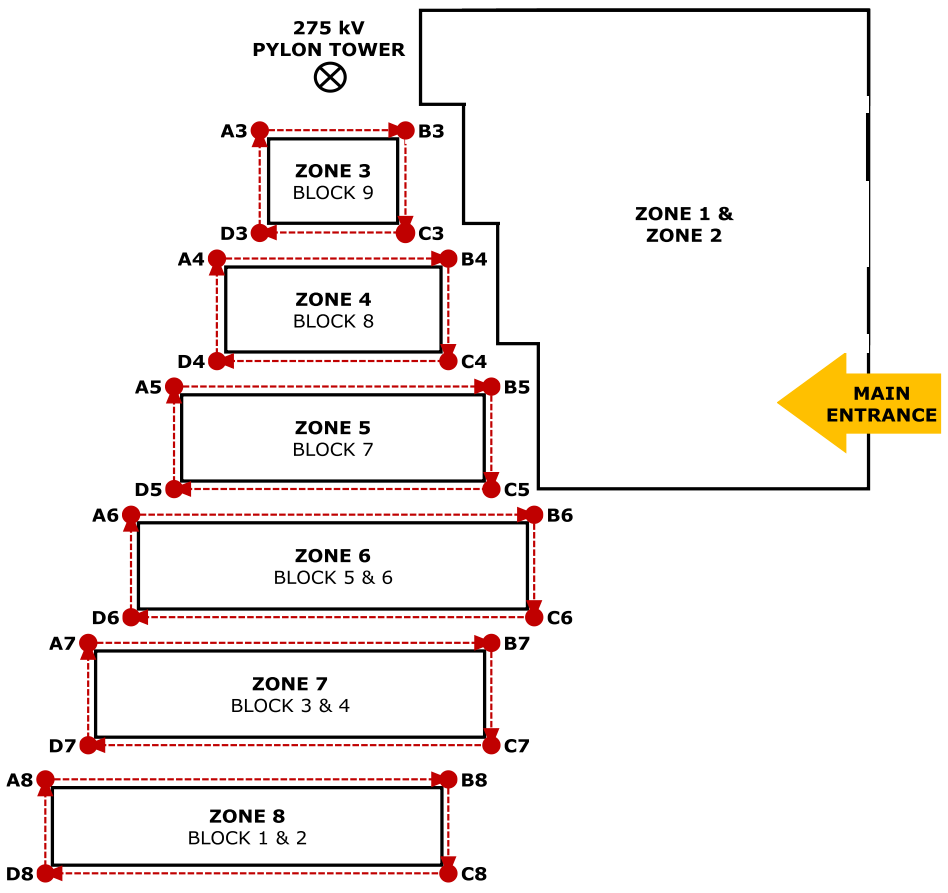

Figure 3. The route for path measurement method

\subsection{Spot Measurement Method}

Spot measurement method was used in this measurement by using Gauss Meter to measure the magnetic field level at a series of spots with selected intervals. The spots were marked on ground level at selected intervals using spray paints and metal nails strapped with danger tape for best visual results when identifying the spots as shown in Figure 5. This method was used to measure magnetic field level from Zone 1 until Zone 5.

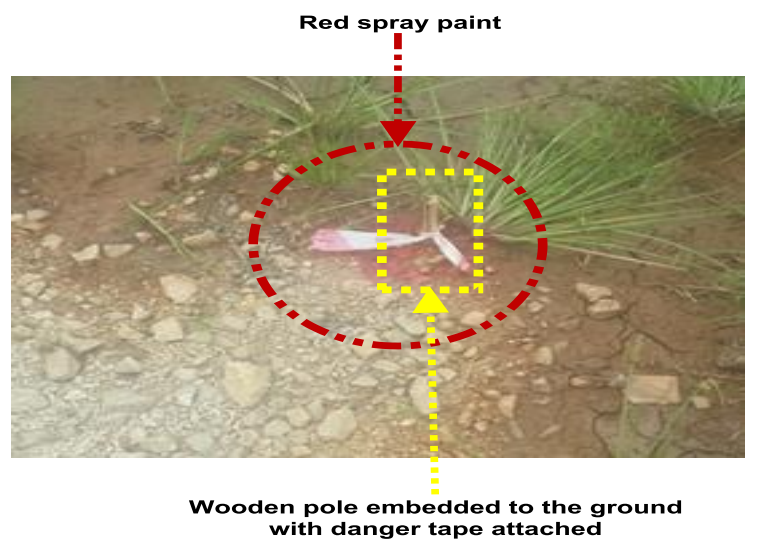

Figure 4. Markings on ground level using spray paint, a piece of wood and dangertape 


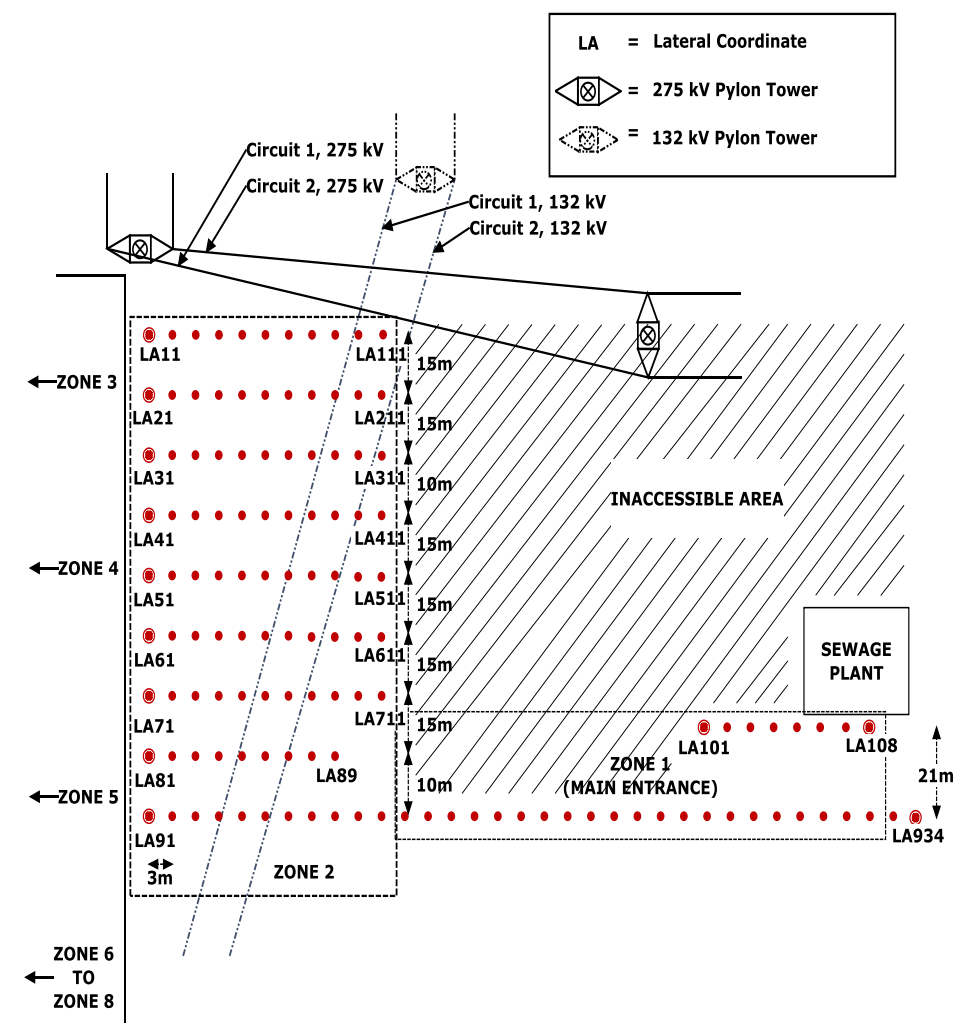

Figure 5. The coordinates for spot measurement method in Zone 1 and Zone 2

Ten Latitude (LA) paths were used to divide Zone 1 and Zone 2 as in Figure 6 namely LA1 to LA10 in order to obtain the most data out of this area. Each path consists of ten magnetic field level measurement spots at 3 meters interval except LA8 and LA10 that only had eight due to obstacles from construction equipment. LA9 and LA10 covered Zone 1 while LA1 to LA9 covered Zone 2.

Spot measurement that was done in Zone 3 to Zone 5 was conducted simultaneously with path measurement method. Starting at point A3 as shown in Figure 4, magnetic field level measurements were recorded manually for every 5 meters travelled using LINDA Wheel that has the capability to show distance travelled.

\subsection{Mock Measurement}

A week before the actual measurement took place, the team members made a site visit to grasp a better view of the actual environment. It was during this visit that the geographical limitations were observed in Zone 1 and Zone 2 that limits the use of path measurement method. Being left with spot measurement method to be used in these two zones, markings on ground level were made representing the spot to measure magnetic field level. Thereafter, mock measurement was done in all of the zones to test the magnetic field meters and to obtain time estimation in order to complete the measurements. Spot measurement method was tested from Zone 1 to Zone 6 while path measurement method was tested from Zone 3 to Zone 6 . Due to the ability to record magnetic field level measurement automatically, path measurement method took less time to be executed compared to spot measurement method. Since the building blocks were still under construction, magnetic field level measurement was not done inside any of the buildings due to safety reasons.

\subsection{Time Management}

During mock measurement, the time estimations in order to execute the measurement methods according to zones were as shown in Table 2:

The perimeter of building blocks in Zone 6, 7 and 8 were the same, thus only time estimation was taken once in Zone 6 that was assumed to be approximately the same for Zone 7 and Zone 8 . Spot measurement method and path measurement method can be executed simultaneously in Zone 3 to Zone 8 . Assuming that spot measurement method was to be used in all zones, it would consume a total of approximately 2 hours for a set of magnetic field level measurement to be concluded. Considering that team members need some time to prepare for the next set of measurement, spot measurement method was excluded in Zone 6, Zone 7 and Zone 8 that were grouped as the least prioritized zones. This action reduced 
the time needed to complete a set of magnetic field level measurement (Zone 1 to Zone 8 ) to approximately 1 hour and 30 minutes leaving spare time for team members to prepare.

The initial plan of this measurement was to measure magnetic field level for every hour starting from 6 a.m. until 6 p.m. seven days. Due to the lack of lighting equipment, measurements could not be executed in the dark. Thus, the duration of the measurement were shortened to eight hours per day starting from 8 a.m. until 4 p.m. for seven days. Judging from the time estimation done during mock measurement, the amount of time allocated to complete a set of magnetic field level including spare time was 2 hours. This allowed four sets of magnetic field level measurement to be executed in one day. The team members were then assigned to two people per shift of 2 hours and took turns completing the magnetic field level measurement.

Table 2. Time estimation to conduct spot measurement method and path measurement method in all zones

\begin{tabular}{ccc}
\hline Zone & Spot Measurement Method & Path Measurement Method \\
\hline $1 \& 2$ & \multicolumn{2}{c}{ Time (min'sec") } \\
3 & $45^{\prime} 0^{\prime \prime}$ & N/A \\
4 & $3^{\prime} 54^{\prime \prime}$ & $2^{\prime} 50^{\prime \prime}$ \\
5 & $7^{\prime} 20^{\prime \prime}$ & $6^{\prime} 0^{\prime \prime}$ \\
$6,7 \& 8$ & $8^{\prime} 48^{\prime \prime}$ & $7^{\prime}$, \\
\hline
\end{tabular}

\section{RESULTS}

Table 3 represents the maximum values of magnetic field level recorded in each zone throughout the measurement. Measurement spots that are located directly underneath the OTL conductor cables should provide higher magnetic field level. Among those measurement spots, the highest magnetic field level recorded was $1.00 \mu$ Tesla in Zone 2 at coordinate LA93. LA93 is located at the midspan of Circuit 1, 132kV OTL that would be the closest distance from conductor to ground.

The second highest magnetic field level recorded was $0.55 \mu$ Tesla in Zone 5 that was located nearest to $132 \mathrm{kV}$ OTL cables as compared to other building blocks. Although the zones in Priority 3 were located far from the $132 \mathrm{kV}$ OTL, the magnetic field level recorded does not differ much compared to zones in Priority 2. All of the maximum magnetic field level recorded in Zone 3 to Zone 8 were located at the upper right corner of each zone that was exposed the most to the $132 \mathrm{kV}$ OTL.

The $275 \mathrm{kV}$ OTL does not provide significant impact to this case study because its rights-of-way were not violated as much as the rights-of-way of $132 \mathrm{kV}$ OTL.

Table 3. Maximum magnetic field level recorded throughout the measurement

\begin{tabular}{ccc}
\hline \multirow{2}{*}{ Zone } & Maximum Magnetic Field Level $(\mu$ Tesla $)$ \\
\hline \multirow{2}{*}{ Priority 1 } & Zone 1 & 0.38 \\
& Zone 2 & 1.00 \\
\multirow{2}{*}{ Priority 2 } & Zone 3 & \\
& Zone 4 & 0.33 \\
& Zone 5 & 0.23 \\
& & 0.55 \\
Priority 3 & Zone 6 & \\
& Zone 7 & 0.16 \\
& Zone 8 & 0.22 \\
\end{tabular}

\section{CONCLUSION}

The highest magnetic field level recorded were directly underneath the $132 \mathrm{kV}$ OTL cables that were only $0.5 \%$ of the maximum permissible magnetic field level proposed by ICNIRP. The magnetic field level may be low for the being, but it will surely increase in the future when the electricity demand and human population increases.

Although the time allocation for a set of magnetic field level measurement had been determined after mock measurement, the actual measurement might take even less or even more time. Inside a construction site, there are many obstacles like construction equipment, construction wastes, lorries and tractors that goes in and out, and also sometimes even animals that may put a halt to the magnetic field level 
measurement process. There are also probabilities of equipment failures and weather change that might disrupt a continuation of data. Though, this paper presents a proper planning and practical method of magnetic field level measurement procedures suitable for this case study or any other case studies which has similar situation.

\section{ACKNOWLEDGEMENT}

Authors gratefully acknowledge the support of UTHM EMCenter's staff members for their valuable contribution throughout the measurement process. Authors also appreciate the financial support provided by ORICC of UTHM under Contract Grant Vot U001 to ensure the success of this project.

\section{REFERENCES}

[1] I. Said and H. B. Hussain, "Computation of Magnetic Field from Quadruple Tower Transmission Lines in Malaysia," in Proceedings of the Universities Power Engineering Conference, (2008).

[2] I. Said, N. A. Rahman, H. Hussain, A. Farag, and T. Juhana, "Evaluation of Magnetic Field from Different Power Transmission Line Configurations in Malaysia, " in Canadian Conference on Electrical and Computer Engineering, (2004), pp. 393-396.

[3] K. Ellithy, S. Al-Suwaidi, and H. Elsayed, "Measuring human exposure to magnetic fields near EHV 400 KV GIS substation and power lines in state of Qatar," in 2011 North American Power Symposium (2011), pp. 1-6.

[4] B. K. Singh, R. S. Sharma, R. Ajumeera, and A. K. Mathur, "Electromagnetic Fields in Environment and Its Health Hazards," in 2008 International Conference on Recent Advances in Microwave Theory and Applications (2008), pp. 558-560.

[5] H. M. Luqman, M. N. R. Baharom, Z. Zainal, I. Ullah, and I. Ali, "Improvement of the Sag Ampacity Carrying Level of Existing 275 kV Overhead Line Tower by Using Re-conductoring Approach," ARPN Journal (2015), pp. 8547-8555.

[6] ICNIRP, "ICNIRP Guidelines for Limiting Exposure to Time-Varying Electric and Magnetic Fields (1 Hz - 100 kHz)," Health Physics, 99(6):818-836, (2010).

[7] IEEE, "IEEE Standard Procedures for Measurement of Power Frequency Electric and Magnetic Fields From AC Power Lines," IEEE Std, pp. 644-1994.

[8] BSI, "BSI Standards Publication for Electric and Magnetic Field Levels Generated by AC Power Systems Measurement Procedures with Regard to Public Exposure," BS EN 62110:2009.

\section{BIOGRAPHIES OF AUTHORS}

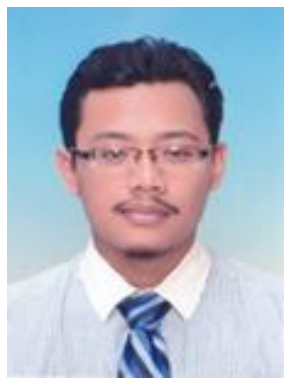

Luqman Hakim bin Mahmod was born in Perak, Malaysia on October 1988. He received the B.E. in Electrical Engineering and his M.Sc. in Electrical Engineering from Universiti Tun Hussein Onn Malaysia (UTHM) in 2010 and 2012 respectively. Currently he is pursuing Ph.D. in Electrical Power Engineering from UTHM.

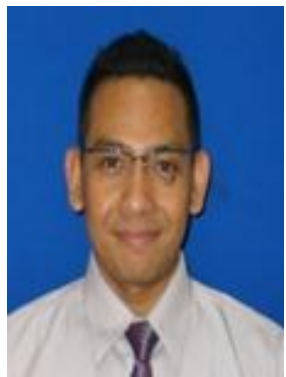

Md Nor Ramdon Bin Baharom was born in Kuala Lumpur, Malaysia on August 1978. He received the B.E. degree in Electrical and Electronic Engineering from School of Computing, Creative Technologies \& Engineering, Leeds Metropolitan University, United Kingdom in 2004. He received the Ph.D. degree from Electrical Energy and Power Systems Group of the School Of Electrical and Electronic Engineering at the University of Manchester in 2010. He is currently working as a lecturer in Department of Power Electrical Engineering of the Faculty of Electrical and Electronic Engineering, Universiti Tun Hussein Onn Malaysia (UTHM), Malaysia. His major research interests include high-voltage insulations, overhead-line design, lightning structure protection, electrical environmental interference impact, composite insulators and flashover of contaminated insulators. 


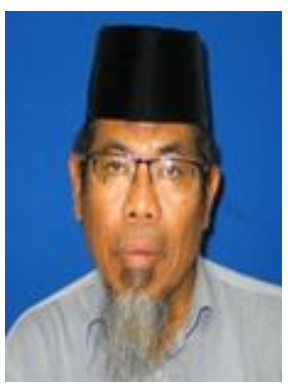

Hussein bin Ahmad was born in Johor, Malaysia on July 1953. He received the B.Sc.in Electrical Engineering and his M.Sc. in Electrical Power System from University of Strathclyde, Scotland, in 1977 and 1981 respectively. In 1986 he received the Ph.D. degree in High Voltage System from University of Manchester Institute of Science and Technology. He is currently working as a professor in Universiti Tun Hussein Onn Malaysia (UTHM). His major research interests include lightning protection and grounding system.

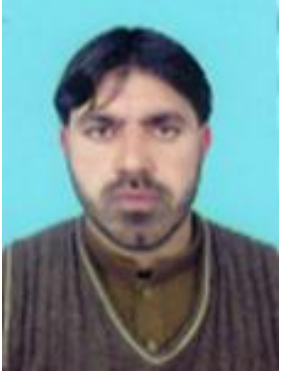

Irshad Ullah was born in District Dir KP, Pakistan on January 1985. He received the B.E.in Electrical Engineering from the Cecose University Peshawar and his M.Sc. in Electrical Engineering from Stafford Shire University, UK in 2010 and 2013 respectively. Currently he is pursuing Ph.D. in Electrical Power Engineering from Universiti Tun Hussein Onn Malaysia (UTHM). 